\title{
Respiratory effects of occupational exposure to tobacco dust
}

\author{
G VIEGI, ${ }^{1}$ PL PAGgiaro, ${ }^{1}$ E BEgliomini, ${ }^{1}$ E VAGHETTI, ${ }^{2}$ P PAOLETTI, ${ }^{1}$ \\ C GIUNTINI ${ }^{1}$
}

From the CNR Institute of Clinical Physiology and II Medical Clinic, ${ }^{1}$ University of Pisa, Pisa, and Occupational Medicine Service, ${ }^{2}$ USL 6, Lucca, Italy

\begin{abstract}
Few investigations of the respiratory effects of occupational exposure to tobacco dust have been carried out and the threshold limit value has not well been established. A cross sectional survey on a sample of 223 male and female workers at a cigar and cigarette factory in Lucca (Tuscany) showed a significantly higher prevalence of wheezing, attacks of shortness of breath with wheezing, dyspnoea, and rhinitis than in a reference population. A trend towards a decrease in forced end expiratory flows according to smoking habit and work duration was evident. Positive skin prick tests were observed in $26 \%$ of men and $23 \%$ of women and were positively associated with duration of work and negatively with cigarette smoking. Thin interstitial space involvement was observed on chest $x$ ray examination in almost half the female workers with more than 35 years exposure. These findings suggest that prolonged exposure to tobacco dust may have negative health effects and that it is advisable to establish a threshold limit value for tobacco dust different from that of inert dust.
\end{abstract}

The effects of tobacco dust on the respiratory tract are not well documented and the American Conference of Governmental Industrial Hygienists has stated that, despite the need to establishing a threshold limit value (TLV), the published documentation is not sufficient. ${ }^{1}$ More than 100 years ago tobacco dust was considered to cause tabacosis, a pneumoconiosis like disease. ${ }^{2}$ Recent studies have reported a low prevalence of chronic respiratory symptoms in tobacco workers and, after acute exposures, allergic reactions with a decrease in ventilatory capacity ${ }^{2} 3$; however, no excess of mortality from lung diseases has been observed. ${ }^{4}$

The aim of the present study was to investigate the effects of occupational exposure to tobacco dust in a sample of workers in a cigar and cigarette factory in Tuscany.

\section{Material and methods}

The Manifattura Tabacchi (MT) in Lucca produces cigarettes and cigars; the tobacco leaves come mainly from Italy and North America. An environmental study, performed before the epidemiological study, showed that total dust concentrations were in the

Accepted 21 April 1986 range 0.7 to $24.9 \mathrm{mg} / \mathrm{m}^{3}$; in four of the 11 sampling sites the TLV for inert dust $\left(10 \mathrm{mg} / \mathrm{m}^{3}\right)$ was exceeded. Moreover, moulds (Alternaria tenuis and various types of Aspergillus) were found, especially in the fermentation room.

At the beginning of the epidemiological study (October 1980) the factory had 907 male and female workers. All were asked to complete a simple questionnaire concerning age, current smoking habit, and duration of employment in the factory; the response rate was $87 \%, 454$ women and 349 men. Men had a unimodal distribution of duration of employment, most of them (319) having worked from one to 15 years. For the purpose of the study they were divided into two groups with less or more than six years employment; women fell mainly into two groups, one composed of older women (164) with more than 35 years at work and the other of younger women (286) with less than six working years; they were subdivided for the study into two groups with less and more than three years at work. The distribution of the labour force reported from the pattern of development of the factory which was marked by two main periods of expansion, one during the last years of the second world war (only women) and one after 1970 when there was an increased consumption of national brand cigarettes. ${ }^{5}$ Since our plan was to investigate 802 
the effects of different durations of exposure to tobacco (short, medium, and long), a random selection was performed taking into account smoking habit (table 1). Among the men who had worked for up to 15 years, 100 subjects were invited, and 89 (40 non- or ex-smokers (NS), 49 smokers (S)) subdivided into two groups of different work duration $(\leqslant 6$ years and $>6$ years) agreed to participate. Among the older women, 60 were selected, of whom 40 agreed to participate in the study (23 NS, 17 S). Among the younger women with less than six years at work, 120 were selected and 93 (47 NS, $46 \mathrm{~S}$ ) subdivided into two groups of different work duration $(\leqslant 3$ years and $>3$ years) agreed to participate. For statistical purposes, the grouping of non-smokers with ex-smokers was decided having assessed by analysis of variance that their values of forced expiratory volume in one second $\left(\mathrm{FEV}_{1}\right)$ did not differ significantly.

On the same afternoon each subject completed the following:

(1) standardised questionnaire for respiratory disease, developed by the Italian National Research Council (CNR) ${ }^{6}$ derived from that of the American National Heart, Blood and Lung Institute (NHLI). The symptoms and diseases used in the analysis were: chronic cough, chronic phlegm, wheezing, attacks of shortness of breath with wheezing and whistling (SOBWHZ), exertional dyspnoea of the first grade, recurrent bronchitis or pneumonia after age 12 (RRD), asthma, and rhinitis;

(2) measurement, by a computerised Hewlett Packard pulmonary desk system, of forced vital capacity (FVC) and derived indexes, according to the protocol of CNR special project on preventive medicine ${ }^{7}$ following the American Thoracic Society statement ${ }^{8}$ : $\mathrm{FEV}_{1}$ forced expiratory flows between 25 and $75 \%$ $\left(\mathrm{FEF}_{25-75 \%}\right)$ and between 75 and $85 \%\left(\mathrm{FEF}_{75-85 \%}\right)$ of FVC, maximal expiratory flows at 50\% $\left(\mathrm{MEF}_{30 \%}\right)$ and at $75 \%\left(\mathrm{MEF}_{75 \%}\right)$ of FVC;

(3) measurement of the diffusing capacity of carbon monoxide in a single breath ${ }^{9}$ (DLCOsb; DL/VA, coefficient of transfer of $\mathrm{CO}$ ) by Morgan Resparameter Mk4;

(4) skin prick tests, only in men and in younger women, according to the protocol of CNR special project on preventive medicine ${ }^{7}$ to the following allergens: pollens (Graminaceae, Compositae, Oleaceae, Parietaria officinalis), moulds (Aspergillus fumigatus, Alternaria tenuis), Dermatophagoides pteronyssinus, animal danders (dog, cat, horse), control and histamine $1 \%$. Moreover, allergenic extracts were prepared from the cured tobacco leaves used in the factory for making the commonest brands of cigars and cigarettes. The response was considered as positive in the presence of a mean weal diameter greater or equal to $5 \mathrm{~mm}$ having subtracted the negative control, and dubious when the mean weal diameter was $3-4 \mathrm{~mm}$.

Standard chest $x$ ray films (posterior and lateral views) were obtained in the same week. Three trained readers separately observed all the radiographs using a modified 1980 ILO/UC classification ${ }^{10}$ to detect perivascular interstitial space involvement (enlargement, blurring, or increased density of the hilum; blurred cardiac outlines; thickened bronchial walls; increased bronchovascular markings); parenchymal interstitial space involvement (fine reticular network, rounded or irregular small opacities, linear shadows); signs of overinflation (reduction in lung density; lowered and flattened diaphragms; increased retrosternal or retrocardiac spaces). A final evaluation was obtained for each radiograph and was derived from the agreement of at least two of the three readers.

As a reference, the population which had been

Table 1 Main features of tobacco workers studied

\begin{tabular}{|c|c|c|c|c|}
\hline $\begin{array}{l}\text { Work duration } \\
\text { class (years) }\end{array}$ & Smoking habit & No & Age (years) & $\begin{array}{l}\text { Specific work } \\
\text { duration (years) }\end{array}$ \\
\hline \multicolumn{5}{|c|}{ Men } \\
\hline$\leqslant 6$ & NS & 23 & $34 \cdot 2 \pm 2 \cdot 7$ & $5.3 \pm 0.8$ \\
\hline$>6$ & NS & 17 & $37.6 \pm 2.9$ & $10.8 \pm 3.0$ \\
\hline$\leqslant 6$ & $\mathbf{S}$ & 21 & $33.6 \pm 1.5$ & $5.2 \pm 0.7$ \\
\hline$>6$ & & 28 & $36.2 \pm 3.0$ & $9.9 \pm 2.5$ \\
\hline \multirow{2}{*}{\multicolumn{5}{|c|}{ Younger women $I 00$}} \\
\hline & & & & \\
\hline$\leqslant 3$ & NS & 21 & $32.1 \pm 2.6$ & $2 \cdot 3 \pm 0.7$ \\
\hline$>3$ & NS & 26 & $33.7 \pm 3.8$ & $4 \cdot 2 \pm 0 \cdot 1$ \\
\hline$\leqslant 3$ & & 22 & $32 \cdot 2 \pm 3 \cdot 2$ & $2 \cdot 2 \pm 0.4$ \\
\hline $\begin{array}{l}>3 \\
\text { All }\end{array}$ & & 24 & $32.5 \pm 3.8$ & $4.1 \pm 0.4$ \\
\hline \multicolumn{5}{|c|}{ Older women } \\
\hline$>35$ & NS & 23 & $58.0 \pm 1.8$ & $38 \cdot 5 \pm 1 \cdot 5$ \\
\hline$>35$ & S & 17 & $56 \cdot 7 \pm 1.3$ & $37.9 \pm 1.2$ \\
\hline All & $\mathrm{NS}+\mathrm{S}$ & 40 & $57.5 \pm 1.7$ & $38.3 \pm 1.4$ \\
\hline
\end{tabular}

NS $=$ Non- and ex-smokers.

$\mathbf{S}=$ Smokers. 
investigated in an epidemiological survey in an unpolluted area of North Italy was used; the characteristics of this population are fully described elsewhere. ${ }^{11 a}$ Briefly, a randomised multistage cluster sample of the general population $(n=3289)$, ages 8 to 64 , was studied by CNR questionnaire and pulmonary function tests (forced expirograms, diffusing capacity, closing volume) with HP pulmonary desk system. From the 801 normal subjects (non-smokers, fully asymptomatic) the reference equations of forced expirograms were derived and applied to the Manifattura Tabacchi workers. Further, a subsample with the same sex, age, and smoking characteristics as the MT workers was selected by the computer and used as a control group for the comparison of symptom prevalence and lung function involvement.

Statistical analysis was performed using the statistical package for the social sciences routines of the University of Pisa computer centre (IBM 370).

\section{Results}

The prevalence of the main respiratory symptoms in the different groups according to work duration and smoking habit is reported in table 2. Among men, there was a relatively constant trend to an increase of prevalence rates in the different groups of NS with short work duration to $\mathrm{S}$ with longer work duration. Several symptoms showed a significant chi square trend: chronic cough $(4 \%, 12 \%, 14 \%$, and $25 \%$ respectively; chi square $=4.28, \mathrm{p}<0.05)$, chronic phlegm $(9 \%, 12 \%, 10 \%$, and $25 \%$; chi square $=4 \cdot 17$, $\mathrm{p}<0.05)$, and wheezing $(0 \%, 12 \%, 29 \%$, and $32 \%$; chi square $=9.84, p<0.01$ ). Rhinitis and asthma were more frequent in NS. When these rates were standardised (using an indirect method) according to the reference population ${ }^{11,11 a}$ with the same age range and smoking habit, significantly higher prevalences were found in tobacco workers for SOBWHZ, dyspnoea, and rhinitis in NS and for wheezing and RRD in S. Among the younger women, the trend to an increase in prevalence rates with an increase in tobacco exposure was not apparent. Comparison with the reference population, however, showed significantly higher prevalences in the tobacco workers for wheezing, SOBWHZ, RRD, and asthma in NS and for wheezing and asthma in S. Among the older women, $S$ showed higher prevalences than NS for all respiratory symptoms; with respect to the reference population, only $S$ showed higher prevalences for wheezing, SOBWHZ, RRD, and rhinitis.

The results of the pulmonary function tests, expressed as percentages of the predicted values, are shown in fig 1 for the male workers. All the indexes derived from FVC and from DLCOsb were in the normal range. From an analysis of variance it was found that the only statistically significant differences (p < 0.01) were found among NS and S with longer $(>6$ y) work duration for DLCOsb $(95.5 v 85 \%)$ and DL/VA $(108.1 v 96.6 \%)$. As regards the small airway tests, there was a non-significant trend to a decrease according to smoking habit and increasing work duration. When the functional data were compared with those of the reference population, a significant impairment of the end-expiratory flows $\left(\mathrm{FEF}_{75-85 \%}\right.$ and $\mathrm{MEF}_{75 \%}$ ) was observed in subjects with longer duration of work.

The younger women with more than three years duration of work showed the highest value of FVE $(108.9 \%)$ and $\operatorname{FEV}_{1}(106.7 \%)$ (fig 2); they also showed the lowest value of $\mathrm{FEF}_{75-85 \%}(80.8 \%)$ and of DL/VA (96.9\%) with respect to the other groups. The value of DLCOsb in NS was significantly lower than in the reference population.

In the older women (fig 3) a non-significant trend to a greater decrease of functional indexes in $S$ than in NS was observed. Expiratory flow rates and DLCOsb

Table 2 Prevalence of main respiratory symptoms

\begin{tabular}{|c|c|c|c|c|c|c|c|c|}
\hline Class & Cough & Phlegm & Wheezing & SOBWHZ & Dyspnoea & $R R D$ & Asthma & Rhinitis \\
\hline \multicolumn{9}{|c|}{ Men } \\
\hline $\begin{array}{l}\leqslant 6 \text { y NS } \\
>6 \text { y NS } \\
\leqslant 6 \text { y S } \\
>6 \text { y S }\end{array}$ & $\begin{array}{r}4 \\
12 \\
14 \\
25\end{array}$ & $\begin{array}{r}9 \\
12 \\
10 \\
25\end{array}$ & $\begin{array}{l}0 \\
12 \\
29 \\
32\end{array}$ & $\begin{array}{c}4 \\
12^{*} \\
0 \\
0\end{array}$ & $\begin{array}{l}17^{*} \\
18^{*} \\
14 \\
21\end{array}$ & $\begin{array}{l}22 \\
18 \\
10 \\
29^{*}\end{array}$ & $\begin{array}{l}4 \\
6 \\
0 \\
0\end{array}$ & $\begin{array}{c}9 \\
18^{*} \\
5 \\
7\end{array}$ \\
\hline $\begin{array}{l}\leqslant 3 \text { y NS } \\
>3 \text { y NS } \\
\leqslant 3 \text { y S } \\
>3 \text { y S }\end{array}$ & $\begin{array}{r}10 \\
8 \\
18 \\
8\end{array}$ & $\begin{array}{r}0 \\
12 \\
14 \\
4\end{array}$ & $\begin{array}{l}14^{*} \\
12^{*} \\
32^{*} \\
17\end{array}$ & $\begin{array}{c}\text { Younger women } \\
5 \\
15^{*} \\
0 \\
8 \\
\text { Older women }\end{array}$ & $\begin{array}{l}24 \\
27 \\
18 \\
25\end{array}$ & $\begin{array}{l}10 \\
27^{*} \\
28 \\
8\end{array}$ & $\begin{array}{c}0 \\
12^{*} \\
5 \\
8^{*}\end{array}$ & $\begin{array}{r}10 \\
8 \\
5 \\
13\end{array}$ \\
\hline $\begin{array}{l}\text { NS } \\
\text { S }\end{array}$ & $\begin{array}{r}4 \\
24\end{array}$ & $\begin{array}{r}0 \\
12\end{array}$ & $\stackrel{9}{41^{*}}$ & $\mathbf{2 9}^{*}$ & $\begin{array}{l}30 \\
59\end{array}$ & $\begin{array}{l}13 \\
47^{*}\end{array}$ & $\begin{array}{r}0 \\
12\end{array}$ & $\stackrel{4}{18 *}$ \\
\hline
\end{tabular}

SOBWHZ = Attacks of shortness of breath with wheezing and whistling.

RRD = Recurrent bronchitis or pneumonia after age 12 .

* Statistically different from reference population by chi square test.

A significant chi square trend was found for cough, phlegm, and wheezing only in men. 


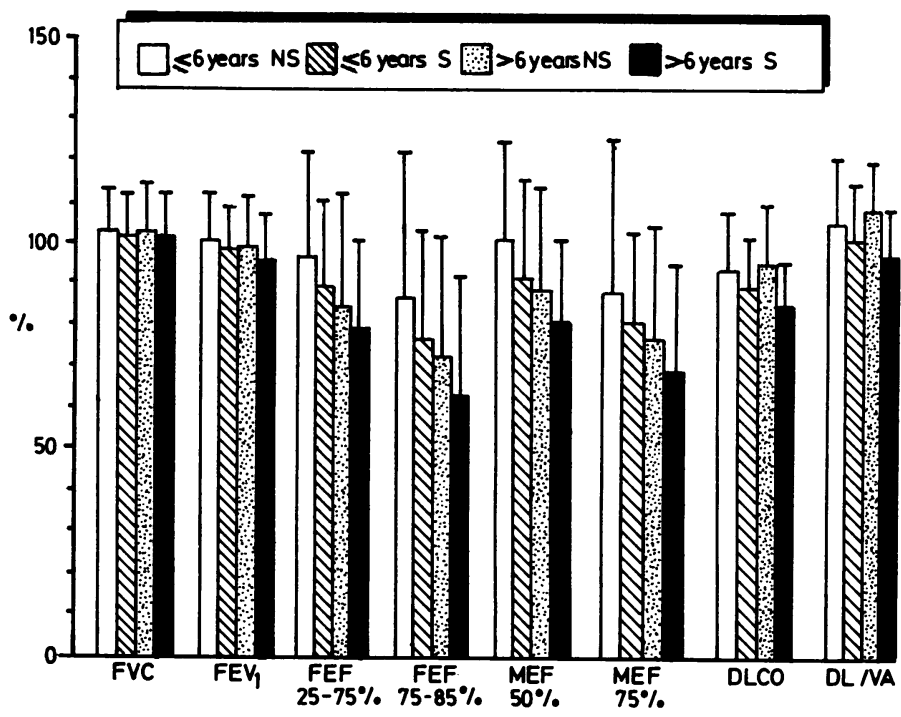

Fig 1 Mean and standard deviation of percentage of predicted lung function values in men according to work duration (less or more than 6 years) and smoking habit. All values are in normal range. Forced mid-end expiratory flows tend to decrease with cigarette smoking and increasing work duration. DLCO $\%$ and $D L / V A \%$ are significantly lower in $>6$ y $S$ than in $>6 y \mathrm{NS}$.

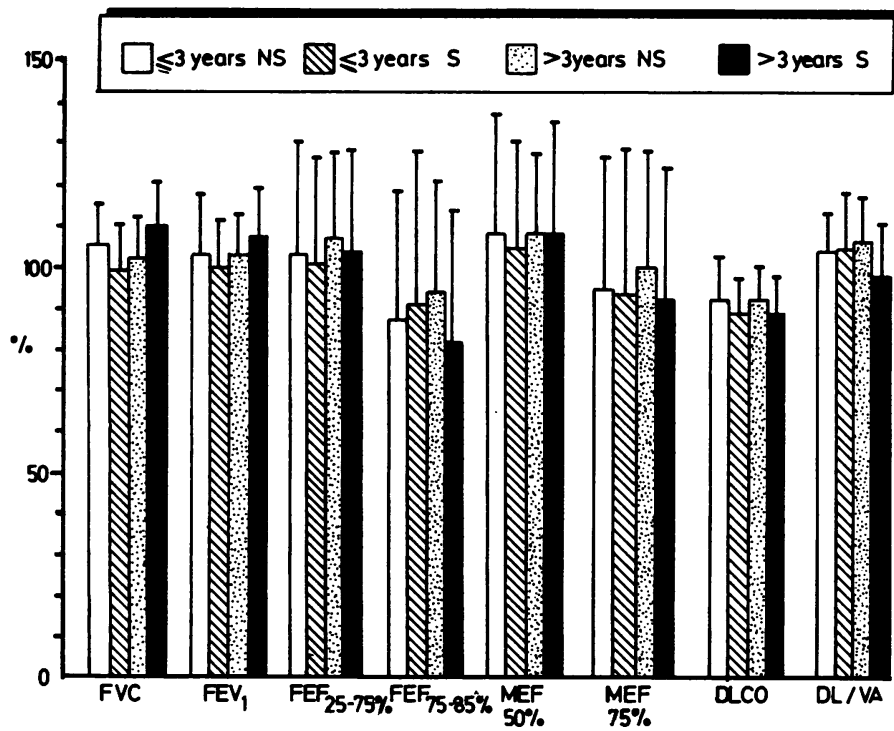

Fig 2 Mean and standard deviation of percentage of predicted lung function values in younger women according to work duration (less or more than 3 years) and smoking habit. All values are in normal range.

were significantly lower than in the reference population, both in S and NS, and $\mathrm{MEF}_{75 \%}$ was lower than the normal limit.

A stepwise multiple regression analysis* between the results of the lung function tests and anthropometric and working features was also performed: in men specific work duration and age accounted for most of the variance in $\mathrm{MEF}_{50}$ and $\mathrm{FEF}_{25-75 \%}$ respectively, whereas pack-years explained that of the

\footnotetext{
*The lists of multiple regression and discriminant analyses are
} available from the authors on request. other lung function parameters; in women (considering both younger and older together), total work duration and pack-years explained most of the variance in FVC and the diffusion indexes respectively, whereas age and height explained the other indexes of the forced expirograms.

The role of work duration was also evaluated using a discriminant analysis* to investigate which functional test could discriminate best between the working groups, considering the smoking categories separately: forced end-expiratory flows and DL/VA in 


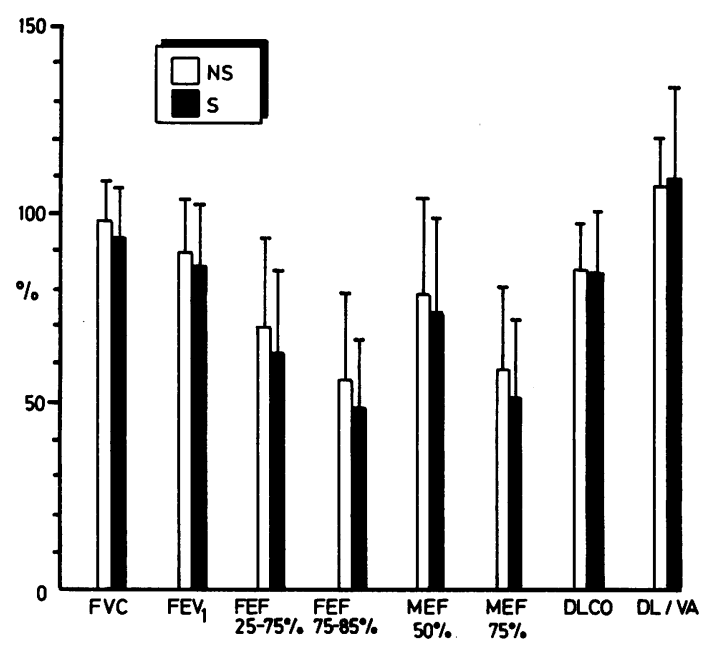

Fig 3 Mean and standard deviation of percentage of predicted lung function values in older women according to smoking habit. S have lower values than NS. In $S, M E F_{75 \%}$ is below the normal limit.

men and forced volumes in younger women discriminated best between the first and second groups; FVC slightly discriminated between the $S$ and NS old women. The percentage of subjects correctly classified, however, was only $52-69 \%$.

As regards the allergenic evaluation (table 3 ) positive skin prick tests were observed in $26 \%$ of the men and $23 \%$ of the younger women; NS had a higher prevalence than $\mathrm{S}$, both in men $(36 \% v 18 \%)$ and in younger women $(29 \% v 18 \%)$. If dubious and positive prick tests were considered together the overall preva- $\overline{3}$ lence of reactive subjects increased to $72 \%$ in men and $\stackrel{\Phi}{\circ}$ to $69 \%$ in younger women. Moreover, in both sexes and smoking categories the prevalence of skin positive and dubious subjects was greater in the groupso with a longer duration of work. When the responses to different groups of allergens were considered, pol- $\overline{\bar{N}}$ lens showed the highest prevalence of positive reac- $\mathbb{\Phi}$ tions both in men and women; moulds and tobaccoo derivatives elicited a few positive responses but $a^{\infty}$ greater number of dubious responses. Positive skin $\vec{\circ}$ reactions to tobacco derivatives were more frequent $\vec{A}$ in younger women than in men, but the prevalence of ${ }^{\omega}$ dubious reactions was similar in both groups. Non- $\bigcirc$ smokers showed a higher prevalence of positive skin $\frac{\Phi}{3}$ reactions to tobacco derivatives compared with smokers; however, the prevalence of dubious reactions was similar in both smoking categories. Finally, $\vec{N}$ the prevalence of dubious skin tests to tobacco extracts was greater in men with the longer duration of work.

The chest $x$ ray findings are reported in table $4 . \vec{O}$ Men showed a significantly higher prevalence of hilar $\mathbb{D}$ abnormalities than women, whereas the older women $\Phi$ had a higher prevalence of fine reticular network. 3 Round or irregular small opacities were seldom $\stackrel{\mathbb{D}}{-}$ observed in any of the groups. Increase in brop $\vec{\theta}$ chovascular markings and signs of overinflation we not significantly different in the men and women nor was a trend to an increase in $x$ ray findings accordif to smoking habit and work duration observed in either men or women.

Table 3 Prevalence (\%) of positive and dubious responses to different groups of allergens in men and younger women

\begin{tabular}{|c|c|c|c|c|c|c|c|c|c|c|c|c|}
\hline \multirow[b]{2}{*}{ Working groups } & \multicolumn{2}{|l|}{ All } & \multicolumn{2}{|c|}{ Dermatoph } & \multicolumn{2}{|c|}{ Pollens } & \multicolumn{2}{|c|}{ Danders } & \multicolumn{2}{|c|}{ Moulds } & \multicolumn{2}{|c|}{ Tobacco der } \\
\hline & Pos & $D u b$ & Pos & $D u b$ & Pos & $D u b$ & Pos & Dub & Pos & Dub & Pos & Dub \\
\hline $\begin{array}{l}\leqslant 6 \text { y NS } \\
>6 \text { y NS } \\
\text { All NS } \\
\leqslant 6 \text { y S } \\
>6 \text { y S } \\
\text { All S }\end{array}$ & $\begin{array}{l}30 \\
44 \\
36 \\
12 \\
21 \\
18\end{array}$ & $\begin{array}{l}35 \\
50 \\
42 \\
41 \\
54 \\
49\end{array}$ & $\begin{array}{r}10 \\
19 \\
14 \\
6 \\
2\end{array}$ & $\begin{array}{r}5 \\
25 \\
14 \\
18 \\
28 \\
24\end{array}$ & $\begin{array}{r}10 \\
25 \\
17 \\
6 \\
18 \\
13\end{array}$ & $\begin{array}{r}\text { Men } \\
25 \\
25 \\
25 \\
29 \\
28 \\
29\end{array}$ & $\begin{array}{l}5 \\
6 \\
6 \\
4 \\
2\end{array}$ & $\begin{array}{r}30 \\
19 \\
25 \\
6 \\
11 \\
9\end{array}$ & $\begin{array}{l}-6 \\
3 \\
4 \\
2\end{array}$ & $\begin{array}{l}25 \\
31 \\
28 \\
23 \\
29 \\
27\end{array}$ & $\begin{array}{r}10 \\
6 \\
8 \\
- \\
-\end{array}$ & $\begin{array}{l}20 \\
37 \\
28 \\
23 \\
32 \\
29\end{array}$ \\
\hline All NS + S & 26 & 46 & 7 & 20 & 15 & 27 & 4 & 16 & 3 & 27 & 4 & 28 \\
\hline $\begin{array}{l}\leqslant 3 \text { y NS } \\
>3 \text { y NS } \\
\text { All NS } \\
\leqslant 3 \text { y S } \\
>3 \text { y S } \\
\text { All S }\end{array}$ & $\begin{array}{l}16 \\
40 \\
29 \\
10 \\
25 \\
18\end{array}$ & $\begin{array}{r}53 \\
44 \\
48 \\
6 \\
33 \\
44\end{array}$ & $\begin{array}{l}-8 \\
5 \\
5 \\
2\end{array}$ & $\begin{array}{r}-8 \\
5 \\
10 \\
4\end{array}$ & $\begin{array}{l}Y o \\
10 \\
20 \\
16 \\
5 \\
8 \\
7\end{array}$ & $\begin{array}{c}\text { ger wom } \\
26 \\
24 \\
25 \\
29 \\
25 \\
27 .\end{array}$ & $\begin{array}{r}-8 \\
5 \\
8 \\
4\end{array}$ & $\begin{array}{r}21 \\
16 \\
18 \\
14 \\
4 \\
2\end{array}$ & $\begin{array}{r}5 \\
12 \\
9 \\
4 \\
2\end{array}$ & $\begin{array}{r}16 \\
8 \\
11 \\
38 \\
4 \\
20\end{array}$ & $\begin{array}{r}5 \\
28 \\
18 \\
8 \\
4\end{array}$ & $\begin{array}{l}31 \\
28 \\
29 \\
33 \\
21 \\
27\end{array}$ \\
\hline All NS $+\mathbf{S}$ & 23 & 46 & 3 & 4 & 11 & 26 & 4 & 13 & 6 & 16 & 11 & 28 \\
\hline
\end{tabular}


Table 4 Prevalence (\%) of main chest $x$ ray findings in tobacco workers

\begin{tabular}{|c|c|c|c|c|c|}
\hline Working groups & $H A$ & $I B M$ & $F R N$ & so & $O$ \\
\hline $\begin{array}{l}\text { Men: } \\
\leqslant 6 \text { y NS } \\
>6 \text { y NS } \\
\leqslant 6 \text { y S } \\
>6 \text { y S } \\
\text { Younger women: } \\
\leqslant 3 \text { y NS } \\
>3 \text { y NS } \\
\leqslant 3 \text { y S } \\
>3 \text { y S } \\
\text { Older women: } \\
\text { NS } \\
\text { S }\end{array}$ & $\begin{array}{l}16^{*} \\
9 \\
25 \\
25 \\
11 \\
4 \\
\frac{8}{8} \\
8 \\
\frac{5}{12}\end{array}$ & $\begin{array}{l}56 \\
48 \\
69 \\
50 \\
56 \\
65 \\
35 \\
54 \\
62 \\
50 \\
56 \\
57 \\
76\end{array}$ & $\begin{array}{l}21 \\
26 \\
31 \\
15 \\
15 \\
12 \\
10 \\
12 \\
10 \\
17 \\
52^{*} \\
43 \\
65\end{array}$ & $\begin{array}{r}2 \\
4 \\
6 \\
- \\
-1 \\
5 \\
- \\
5 \\
12\end{array}$ & $\begin{array}{l}22 \\
30 \\
13 \\
20 \\
22 \\
16 \\
15 \\
15 \\
14 \\
24 \\
25 \\
35 \\
12\end{array}$ \\
\hline
\end{tabular}

*Significantly different from other groups.

$\mathrm{HA}=$ Hilar abnormalities.

IBM = Increased bronchovascular markings.

FRN = Fine reticular network.

SO $=$ Small opacities.

$\mathrm{O}=$ Overinflation.

\section{Discussion}

In a survey of female non-smoking tobacco workers with a mean exposure of 15 years Valic et al found a lower prevalence of chronic bronchitis (7.5\%) and nasal catarrh (11\%) and a higher prevalence of chest tightness $(11 \%)$ and wheezing $(10 \cdot 1 \%)$ than in a control group. ${ }^{2}$ Our non-smoking tobacco workers, exposed to similar dust concentrations but with less exposure time, showed similar prevalences, especially for cough and phlegm. When we compared these values with those derived from a reference population ${ }^{11 a}$ we found that even a short term occupational exposure to tobacco dust may induce raised prevalences of symptoms referable to chronic obstructive or allergic diseases or both. In older women a stronger effect of cigarette smoking in inducing chronic respiratory symptoms was evident.

The analysis of the pulmonary function tests suggested that men were possibly submitted to a combined effect of cigarette smoking and tobacco exposure: in fact, the mid-end expiratory flow indexes, although not reaching the significance level because of their high variability, ${ }^{12}$ showed a constant decrease in the range from first group NS to second group $\mathrm{S}$. Also the significant differences of DLCOsb \% and DL/VA \% between NS and S of the second group may be explained by higher cigarette consumption and work duration. The younger women, however, did not show a constant trend to a decrease in lung function tests with increasing occupational exposure; this difference between men and women may be due to shorter exposure experienced by the younger women. The older women in the study showed the lowest functional values and $\mathrm{MEF}_{75 \%}$ of $\mathrm{S}$ was below the normal limit: these findings suggest a possible negative effect of long term exposure to tobacco dusts on the small airways.

These considerations are confirmed by a comparison with the lung function tests of the reference population which suggests a possible dose effect trend: in fact, all the results of the older women, the mid-end expiratory flows of the second group of men and the end expiratory flows of the younger women were lower than those of the reference population.

By stepwise multiple regression analysis we confirmed that pack-years is a useful index in men ${ }^{14}$ accounting for the effect of cigarette smoking on most functional parameters. Specific work duration explained only part of the variance in $\mathrm{MEF}_{50 \%}$. In women, according to the broader range of anthropometric and work duration data, the variance of most functional tests was accounted for by age, height, and total work duration (only for FVC). Pack-years was confirmed to be a useful predictor for diffusion indexes.

The discriminant analysis between the working groups on the basis of the pulmonary function tests gave no consistent information: a trend for a separation of the working groups with some functional indexes was present but, in general, the percentage of cases correctly classified to the group was small.

The prevalence of subjects with positive skin tests was $26 \%$ in men and $23 \%$ in younger women: these figures are lower than those found in a study of a general population, ${ }^{14}$ though using different reading criteria, but they are higher than those found in a group of mill workers in the same town. ${ }^{15}$ The finding of a higher prevalence of positive skin reactors among NS, possibly in agreement with the higher prevalence of allergic rhinitis, seems to confirm the results obtained by Burrows in an epidemiological survey of 
a general population. ${ }^{16}$ The number of positive skin reactions to moulds and to tobacco derivatives (both present in the working environment) was small, but there were many dubious reactions to these allergens; moreover, a positive association between skin reactions and work duration was noted. As in clinical practice it is common to observe in atopic subjects that the size of skin reactions to moulds is smaller than to pollens the data suggest the possibility that tobacco dust and moulds would cause irritant and allergic effects ${ }^{23}$ on the airways of exposed workers and this assumed importance as risk factors for chronic obstructive lung disease. ${ }^{16}$

Finally, few small opacities were seen on the chest $x$ ray films: this does not seem to confirm the previous hypothesis that occupational exposure to tobacco dust could cause a typical pneumoconiosis, ${ }^{2}$ though the finding of a considerable prevalence of fine reticular network involvement in the older woman may be interpreted as a sign of deposition of tobacco dust in the interstitium and may be related to their low values of DLCOsb\% and $\mathrm{MEF}_{75 \%} \cdot{ }^{17}$

In conclusion, our data suggest that the effects of occupational exposure to tobacco dust, both in terms of increased symptoms and impairment of lung function, become evident after several years exposure. These findings, together with the relatively high prevalence of skin reactors, may be considered risk factors for chronic obstructive lung disease and confirm the need to establishing a TLV for tobacco dust and to performing periodic checks of the environmental and health conditions of these workers.

We thank Dr P Fazzi, E Fornai, F Di Pede (University of Pisa), Dr G Toma (USL 1 Aulla), and Dr M Filieri and Dr P Giovannetti (USL 6 Lucca) for their help in data collection. We extend our appreciation to Dr MD Lebowitz (University of Arizona) for the critical review of the manuscript and for many helpful suggestions about statistical analysis.

This study was supported by the special project on chronic obstructive lung disease of the Italian Research Council (CNR), Contract No 80.01098.83.

\section{References}

1 Threshold limit values for chemical substances and physical agents in workroom as adopted by the American Conference of Governmental Industrial Hygienist. J Occup Med 1974; 16:39-49,261.

2 Valic F, Beritic D, Butkovic D. Respiratory response to tobacco exposure. Am Rev Respir Dis 1976;113:751-5.

3 Gleich G, Welsh P, Yunginger J, Hyatt R, Catlett J. Allergy to tobacco: an occupational hazard. $N$ Engl J Med 1980;302: 617-9.

4 Blair A, Berney BW, Heid MF, White DW. Cause of death among workers in the tobacco industry. Arch Environ Health 1983;38:223-8.

5 Giuntini C, Paoletti P. Epidemiologia delle malattie polmonari in Italia. Aggiornamento del Medico 1983;3:333-9.

6 Fazzi P, Viegi G, Paoletti P, et al. Comparison between two standardized questionnaires and pulmonary function tests in a group of workers. Eur J Respir Dis 1982;63:168-9.

7 CNR. Special project on preventive medicine-chronic obstructive lung disease: methodology for execution of epidemiological surveys on chronic obstructive lung disease in Italy. CNR (in press).

8 Ferris BJ. Epidemiology standardization project. Am Rev Respir Dis 1978;118(part 2):55-88.

9 Cotes JE. Transfer factor (diffusing capacity). Bull Eur Physiopathol Respir 1983;19(suppl 5):39-44.

10 Instructions pour l'utilisation de la classification internationale du BIT des radiographies de pneumoconioses. Geneve: Bureau International du Travail, 1980.

11 Paoletti P, Viegi G, Pistelli G, et al. Reference equations for the single breath diffusing capacity: a cross sectional analysis and effects of body size and age. Am Rev Respir Dis 1985;132: 806-13.

11a Paoletti P, Pistelli G, Fasai $P$, et al. Reference values for vital capacity and flow-volume curve from a general population study. Bull Eur Physiopathol Respir (in press).

12 Black RA, Offord K, Hyatt RE. Variability in the maxima expiratory flow-volume curve in asymptomatic smokers and in non-smokers. Am Rev Respir Dis 1974;110:282-92.

13 Burrows B, Knudson RJ, Cline MG, Lebowitz MD. Quantitative relationship between cigarette smoking and ventilatory function. Am Rev Respir Dis 1977;115:195-205.

14 Barbee RA, Lebowitz MD, Thompson HC, Burrows B. Immediate skin test reactivity in a general population sample. Ann Intern Med 1976;84:129-33.

15 Filieri M, Vaghetti E, Paggiaro PL, Giovannetti P, Loi AM. Allergopatie respiratorie nei lavoratori esposti a grano e derivati: dati preliminari. In: Progressi nelle conoscenze sui meccanismi dell'asma bronchiale. Padova: CLEUP, 1982:113-5.

16 Burrows B, Lebowitz MD, Barbee RA. Respiratory disorders and allergy skin test reactions. Ann Intern Med 1976;84:134-9.

17 Becklake MR. Asbestos-related diseases of the lung and pleura: their epidemiology and implications for clinical practice. $\mathrm{Am}$ Rev Respir Dis 1976;114:187-227. 